\title{
Chapter 10: The use of technology to build digital communities
}

\section{Michelle Bugby and Helen Caldwell}

\section{Introduction}

In today's digital world social media has the potential to strengthen and broaden communities. It can provide a bridge between on and off-line communication, helping to strengthen links between children, parents and practitioners as they engage in shared activities (Carter Olson, 2016). Online communities can serve as an audience for sharing children's digital products and experiences with a wider audience, and, as Magos et.al. (2013) suggest, international interactions can build intercultural understandings. When technology is used to build links between children across the world it can act as both a window and a mirror for young children: a 'window' to help them understand each other's cultures and a 'mirror' to help develop their own identity (Cox and Galda, 1990).

This chapter addresses the following themes:

- the challenges and benefits of using online communities to enhance children's learning;

- how practitioners might use digital media in their daily interactions with children and as part of their own professional networking activities;

- the role of technology in establishing links between children's homes and early years settings.

The chapter offers examples of these themes in practice through a detailed case study of how The Leicestershire Early Years Writing Project used technology to build communities of practice among practitioners, parents and children.

A key consideration throughout the chapter is the fact that digitalisation has become a feature of our lives and that it can potentially support the development of social learning within online communities. On the other hand, it is also important to revisit the long standing debate about the developmental appropriateness of the use of digital technologies with young children, particularly in relation to their social development. The chapter includes a discussion about the role of online interaction and engagement in communities, giving 
thought as to how they can positively enhance the lives of our children and those who care for them in today's society.

\section{Children's use of digital technologies}

Recent technological developments such as the growth of mobile devices and ubiquitous connectivity have led to significant changes in the way we communicate. Children are increasingly immersed from an early age in a media-rich and connected world. More than seven billion mobile devices such as iPads, tablets, e-readers and smartphones are now connected to the Internet (Flewitt et al., 2014). And as children observe the adults around them using mobile technologies to communicate, work, play, and to source information throughout their daily lives, it seems natural that they too will be keen to harness these technologies for their own purposes. 'Interactive technologies have not only transformed the way our young children learn and play, but also how they behave in society and orient towards their future' (Dhir et al., 2013: 706).

Even the youngest children show a natural attraction to mobile devices; they are fascinated by the way they can interact with moving images and sounds through touch (Neumann, 2014). Mobile devices have the potential to develop children's multimodal sensory systems (Smith \& Gasser, 2005), through their combinations of sound, still and moving images.

Although their fine motor skills are still developing, touch interfaces make it possible for young children to access new learning opportunities and unprecedented amounts of information at the touch of a button or swipe of a screen. And they can often do this as part of their everyday lives, increasing the opportunity for 'incidental' learning (McPake et al., 2013:422), which is instinctive, unplanned, immersive and often unintentional. Children's independent use of digital technology can thus enable them to build a rich bank of knowledge from an early age.

\section{Vignette 1}

A clear example of this is drawn from a study by McPake et al., (2013) who observed a nine month old baby pick up a toy mobile phone and talk into it. Even though the child had only reached the babbling stage of development and had no recognisable words, he knew that 
mobile phones were a significant feature in his home and that they were used for communicating with others.

This example not only demonstrates incidental learning, but also illustrates Buckingham's (2004: 2) belief that 'children develop media literacy even in the absence of explicit attempts to encourage and promote it'.

Media literacy is the ability to fluently use multiple modes such as symbols, photos, narration, sound and video alongside text as a means of expression and to access meaning (Kress, 2010). Family members' frequent use of texting or other screen-based communication such as Skype, Facebook and WhatsApp models the use of media for communication. Creating and sharing media artefacts such as narrated slideshows, films, talking books or posters offers an exciting channel of communication for emergent writers, allowing speech, gesture and visuals to support writing development. The potential to share the resulting products with a range of audiences can be a powerful motivator for young children.

For older children, mobile devices connected to the Internet offer personalised access to a host of educational resources, allowing them to access, retrieve and process information at a pace that suits them. Information literacy is a vital skill: they need to develop critical thinking skills to evaluate the information they encounter and to distinguish what is credible or relevant for themselves.

\section{Children's Digital Communities}

Children undoubtedly learn a great deal from their parents and teachers, but they also learn from each other, and this can be facilitated by digital collaboration and online sharing amongst communities of learners. Engaging with peers through technology allows a sense of belonging to develop; even at an early age children like to feel that they 'fit in.' Digital learning communities can create meaningful emotional bonds as young children exchange knowledge and information with each other whilst using multimedia for communication. If their activities are carefully managed, they can safely participate in social networks outside their immediate community from an early age. 


\section{Vignette 2}

This short vignette provides an example of incidental learning within a community of learners:

'The hole in the wall' (Mitra, 2012) experiment positioned a computer in a wall in the heart of the New Delhi community for the villagers' use. The children in particular, with no prior experience of technology, learnt to use the computer with minimum intervention. The New Delhi children learnt through the direct result of joining a social community working towards a common goal. They solved problems together, motivated by the desire to be successful and to gain status in their community.

As this example shows, peer to peer online interactions can enable children to build virtual communities where they can discuss, collaborate, and share ideas and feelings.

Research on 2-8 year olds' interaction with iPads carried out by Michael Cohen Group \& U.S. Department of Education (2011) suggest that children quickly learn how to navigate app functions and move with ease from one application to another. Using such technologies is often described as mobile learning, 'as a means to extend learning beyond the classroom' so that children catch glimpses of the outside world (Clarke et al., 2013:5). Many researchers draw a positive correlation between the use of mobile devices and educational engagement (Hutchison et al., 2012; Chiong et al., 2012).

Despite the acknowledged benefits of mobile learning (Sharples et al., 2009); there is still some ambivalence towards the integration of technologies in classrooms. This could be due to concerns that they are developmentally unsuitable and pose a risk of exposing young children to inappropriate content (Galloway, 2009).

Similarly, many early years forums draw attention to the fact that children are spending an increasing number of hours per week engaged with screens of all kinds, including mobile technologies such as smartphones, tablets, handheld game devices, and game consoles (Common Sense Media 2011). There are worries about the amount of screen exposure leading to attention difficulties, low academic performance, aggression or even obesity (Sigman, 2012); some think that the use of social media can hinder children's ability to make 
real-world friends, and others wonder whether fewer opportunities to engage with the physical world can inhibit children's imagination.

Sigman (2012), draws attention to the biological effects of technology use such as the potential impact of increased dopamine production on language and cognitive development. He suggests that children under the age of two years should not have any screen time and that it should be significantly restricted for pre-schoolers.

Lindahl and Folkesson (2012) found that early childhood practitioners' beliefs and attitudes influence their technology implementation, making a distinction between practitioners who embrace technology and those who feel that technology threatens their traditional beliefs and teaching philosophies. The latter group often see a need to balance the increased use of technology at home with rich hands-on 'real-life' experiences at school to ensure children's healthy and holistic development. This finding highlights the need to evaluate our use of technology to make sure that it enhances rather than replaces real world engagement in our settings and schools. Technology needs to be embedded meaningfully in the curriculum so that it adds to the learning experiences of young children. One way of achieving this is to use technology to strengthen the connections between children and their communities. For example, rather than taking the place of face-to-face activities such as sharing conversations or reading stories together, technology can serve as a catalyst to extend opportunities for social interaction. This might be by using tools such as Skype to connect classrooms, by online posting and commenting on blogs or class websites, or through the use collaborative online spaces to swap and share digital artefacts. In this way, carefully managed technology use can be a developmentally appropriate practice that will give children the skills to participate in today's social, economic and cultural digital landscapes (Parette et al., 2010:339).

\section{Point for reflection:}

- What value does mobile technology bring and what affordances can it offer to children in the formative early years?

For children to be able to participate in contemporary culture, then, it is essential for early childhood practitioners to design digital learning environments that allow children to be active participants engaging in joint inquiry, discussions, play, challenges, and investigations. 
When used purposefully and positively, the integration of technologies in the classroom has the potential to reframe children's thinking and learning, and create new concepts of work and play.

\section{Practitioners' Digital Communities of Practice to support Children's Development}

If they are to achieve the goal of using technology creatively for teaching and learning, then practitioners need support and guidance. One way of achieving this is by fostering a community of practice $(\mathrm{CoP})$, for themselves enabling them to learn through peer support, collaborative working and resource sharing. Lave and Wenger's notion of Communities of Practice (CoPs) is 'groups of people who share a concern or a passion for something they do and learn how to do it better as they interact regularly'(Wenger, 2014: 1). Early years practitioners may meet face-to-face socially or at work, or they might participate in online or virtual communities of practice.

Practitioners are beginning to recognise the potential for social media to provide opportunities for sharing and learning with like-minded peers around the world. They make use of a range of channels of communication, such as FaceBook, Google Plus, Whats App, Twitter and Pinterest to share their passion for supporting the early years. Social media provides a platform for the international exchange of ideas across a variety of teaching contexts and backgrounds, which strengthens the sense of a professional community.

Technology can also be used in a more structured way to support and extend face-to-face continuing professional development (CPD) events such as Teachmeets, and it can facilitate ongoing interaction between practitioners engaged in CPD over time. Ideas from these digital networks can provide the stimulus and inspiration needed to create more effective provision for young children.

Participants of online CoPs tend to draw together for informal knowledge building by interacting regularly, sharing knowledge and best practices. This helps to reduce the feelings of disconnectedness or isolation that early years educators often experience. There is a shared domain of expertise or 'collective competence' that is valued by the group, which leads to the development of a repertoire of resources and strategies as the group solves problems together, seeks information from each other, reuses solutions and evaluates new developments in their 
field (Wenger, 2014: 5). This interplay of talking, doing and sharing helps to build individual and group expertise, and provides an environment for continuous professional learning.

Each participant in the online community can feel a sense of connectedness, of shared passion and a deepening of knowledge by sharing experiences, problems and solutions, resources and tools, all of which contributes to the development of their pedagogic knowledge. Belonging to an online CoP thus gives increased agency to practitioners as it cuts across geographical boundaries and formal structures, and enables them to take collective responsibility for the direction of their learning. A fundamental idea of online CoPs for educators is that effective learning in the field is on-going and social rather than discrete and individual.

One of the critical factors determining a virtual community's success is its members' motivation to actively participate in community knowledge generation and sharing activities. Participants of online CoPs may hesitate to contribute out of lack of confidence or fear of criticism. However, Wenger (2000) suggests that group discourse within a CoP leads to deeper levels of knowledge building. Similarly, Araujo recognises that not only new knowledge, but also skills are discursively produced during collaborative conversations and networking activities (Araujo, 1998:321). Self-directed involvement by the participants is therefore crucial to the success of the community. Unlike face to face interaction, online CoPs allow for shifts in the adoption of roles based on areas of expertise; at any point in time participants may assume the role of a novice or expert, making the process of knowledge transfer more fluid.

Point for reflection:

- Are practitioners choosing to ignore the new ways of learning with technology by continuing to use traditional methods?

\section{A case study from practice:}

\section{The Leicestershire Early Years Writing Project's use of technology to build communities of practice}


This case study draws examples from a professional development project involving early years practitioners and the four and five year olds they taught, to illustrate ways in which technology can support networked social learning.

The Leicestershire Early Years Writing Project, 'Putting the Wow into Writing', run in partnership with the Leicestershire Local Authority and the University of Northampton, aimed to build a community of practitioners engaged in developing approaches to supporting children in early writing skills through a year-long series of professional development activities. These practitioners shared a common goal of creating their own communities of writers amongst the children, families, teachers and the wider community involved in their settings and schools, believing that such an approach would make writing exciting, purposeful and fun. The project viewed learning as a social process, recognising the way in which knowledge can flow back and forth between layers of nested communities (Triggs and John, 2004). As Triggs and John suggest, a non-linear model of learning through interrelated and overlapping communities can create fertile conditions for teachers' professional growth, as well as for teaching and learning in early years settings and schools.

Technology supported the learning process for the Leicestershire teachers and children in various ways. Around forty practitioners shared ideas in an online community space using Google Plus (http://bit.ly/2vTCGZB). A quick scroll through their posts shows that they represent a colourful tapestry of examples from practice. The use of images enabled them to quickly share ideas as they evolved. A strong visual aspect was important as much of the work was based on the use of hands-on or outdoor experiences to stimulate imaginative writing. The online space enabled them to document their use of inspirational starting points such as missions, mysterious events or investigations, to prompt lively discussions and independent writing. It charts the development of their practice over time, as well as the interactions between children, parents and the wider community. As a result, it provides a bridge between the face-to-face workshops and the transfer of ideas to effective practice, allowing practitioners to develop shared meanings over time. In this way, the growing collection of examples from practice stimulates an iterative creative process as practitioners use each other's posts as building blocks to construct new ideas. 
(2) Re

was inspired by Alexandra's pet naming writing, so when our new caterpillars arrived I asked the children to think of names for them. We had lots of giggles on the carpet thinking of names. I put the caterpillars on a table with name sheets and magnifying glasses. I also made this the 'Mega Job' which means all the children have to visit the table, do the task and add their brick to the tower. They didn't need much encouragement as they were keen to see the caterpillars.
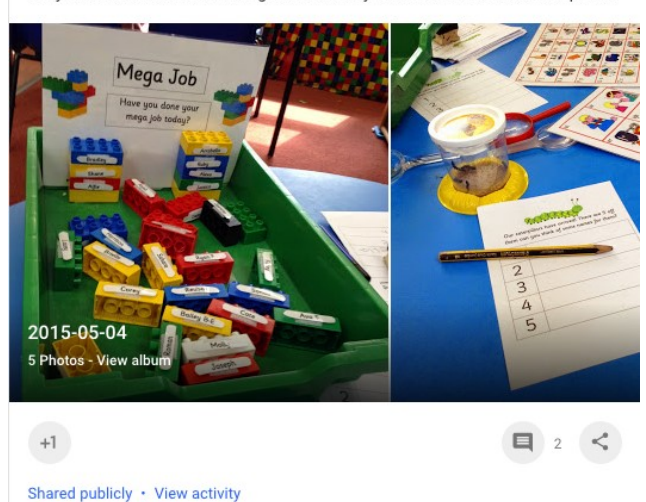

cly · view activity

Gillian Sykes 0 mer

Love it. Love the names as well! Also love that you were inspired as part of our community

Harby R

I like the self-registering/mega jobidea! Might magpie that! You can also use lego bricks for sentence building....my boys love it! I'll get them out today and try and get a few photos!
Alexandra Swan + 'Putting the Wow in Writing' $\vee$

Parents imagination Morning

The children had been learning all about Jack and the Beanstalk! On the Monday the children made their own magic beans and talked about what might happen if they grew! The next morning the parents were invited in for an imagination morning (we didn't mention writing- as some parents are put off by this!) the children spent the morning creating their own magical lands- of what might be at the top of their beanstalk! They then labelled their lands and wrote about what it is like there! For the children whose parents didn't come- they still made their own magical lands and then we sent pictures home for the children to share and write about with their family at home.
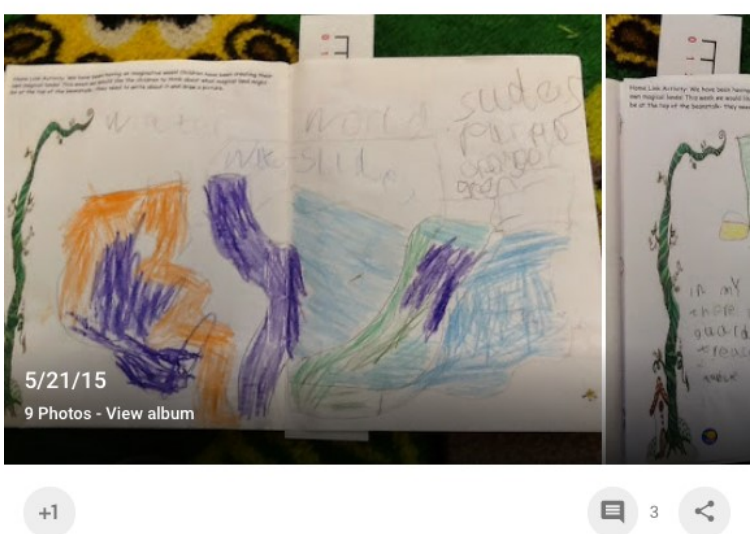

Shared publicly $\cdot$ View activity

Gillian Sykes Owner

What a great achievement Alex. Did you get many parents?

Shona Lewis Moderator

Another great way to involve parents. Thank you for sharing.

Shona Lewis Moderator

Just to let you know Alex that I shared your imagination morning with one of my $\mathrm{Yr} 1$ students who is very creative. She thought it was a brilliant idea and $i$ she is going to invite her parents in. She will then use it to get the children to change the setting in Jack and the Beanstalk when they rewrite the story. Many thanks for your inspiration. Keep up the good work.

Figures 1 and 2: Example posts from the online community, 'Putting the Wow in Writing'.

In the first example above, Rebecca posts an example of a writing activity that builds on an idea from another member of the community. She receives positive feedback from the course tutor and from Harby, who says that she will 'magpie' the idea and extend it to create opportunities for sentence-building in her own setting.

In the second example, Alexandra describes a shared 'imagination morning' for parents and children. This idea is picked up by Shona who has a plan for taking it further.

These examples show how the online community supports peer to peer learning arising out of social behaviour. The transfer of ideas to classroom practice relies on an interplay between two complementary processes, talking and doing, and the images represent communal knowledge which can be assimilated and built upon. This fits in with Wenger's notion that a 
balance of participation (interaction) and reification (making something real) is a prerequisite for social learning in an online community of practice (Wenger et. al., 2009):

'Participation involves acting and interacting, and reification involves producing artefacts (such as tools, words, symbols, rules, documents, concepts, theories, and so on) around which the negotiation of meaning is organized.'

(Smith et. al. 2017, p.210).

It also resonates with theories of connectivist learning which describe a process of learning occurring naturally through making connections with people and resources within an environment mediated by technology (Saadatmand, M., \& Kumpulainen, K., 2014).

The opportunity to interact through comments provided practitioners with encouragement and advice from their peers, and the course leaders took an active role in nurturing the embryonic community:

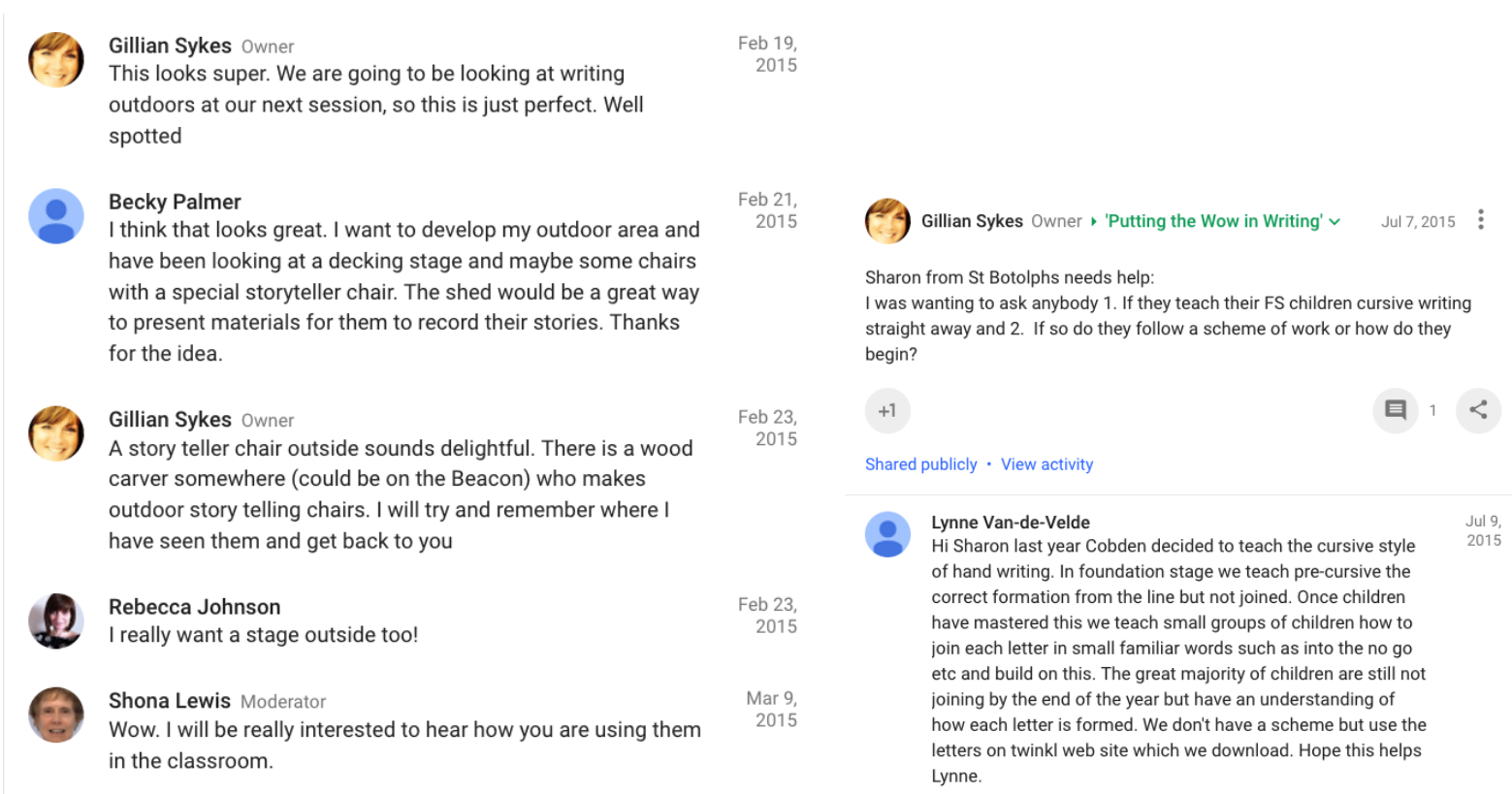

Figures 3 and 4: Interactions between course leaders and participants in the online community

As they explored their theme of inspiring young children to write through this process of online posting and discussion, the practitioners were engaged in the three dimensions of a community of practice identified by Wenger (1998): mutual engagement, joint enterprise and shared practice. They share a belief that the process of children learning to write is continuous, involving transcription and composition. A dance metaphor is repeatedly used to suggest that writing can be a joyful shared experience; 'we want children to kick off their boots and put on their dancing shoes'. 
Alongside the online community, content curation tools supported the collective knowledgebuilding process within the project. For example, the curation of links and online resources was facilitated by the use of Padlet (https://padlet.com/helencaldwell/wowinwriting) and Pinterest (https://www.pinterest.co.uk/helencaldwel/resources-for-eyfs). Content curation is a key aspect of professional practice, as it helps to organise complex sources so that practitioners can find relevant material and contextualise it within their own settings to create new meanings, which they can then share with a wider audience. The Digital Curation Centre (DCC), a consortium of universities instigated by JISC, describes this process as a curation cycle (see http://www.dcc.ac.uk/resources/curation-lifecycle-model).

In addition to this, membership of the community enabled the practitioners to develop the expertise and confidence to contribute to a digital publication of case studies from practice that represented their shared understandings (http://bit.ly/1PSQi9U). In this collaborative book, teachers reported that they had developed a better partnership with parents and families because of their involvement in the project, and were finding ways to further inform and involve them in supporting children's writing development. They agreed that key activities enhancing children's writing were experiential learning, social interaction and the involvement of the wider community in celebrating achievements.

At the end of the project practitioners organised a conference to disseminate to a wider audience of peers. Quotes from the conference evaluations recognise the social nature of the learning, and indicate that the practitioners' community became a source of inspiration for others:

What inspired you?

The passion of the teachers involved in the project

Lovely to spend a day with other like-minded people

I can't wait to go back to school and get started

Taken together, the online community, the curated resources and the digital publication demonstrate how technology can strengthen an emergent community of practice by creating a hub for the co-creation of knowledge. Learning opportunities are amplified as the collective potential of the group exceeds that of the individual, an idea highlighted by Johnson (2001);

The learning that evolved from these communities is collaborative, in which the collaborative knowledge of the community is greater than any individual knowledge. (Johnson, 2001, p34). 
The sharing of ideas with an authentic audience provided an impetus for children's writing, as well as for their teachers. Within the classrooms and settings, technology was used to support writing by making it a collaborative and social activity that was embedded into the setting's culture, underpinned by talk and real world exploration. For example, in one early years environment children used the app Seesaw to make voice recordings to accompany their writing, and these were instantly shared with parents. Another practitioner provided opportunities for children to independently use a blog to share writing and photos with parents, who then responded back with comments.

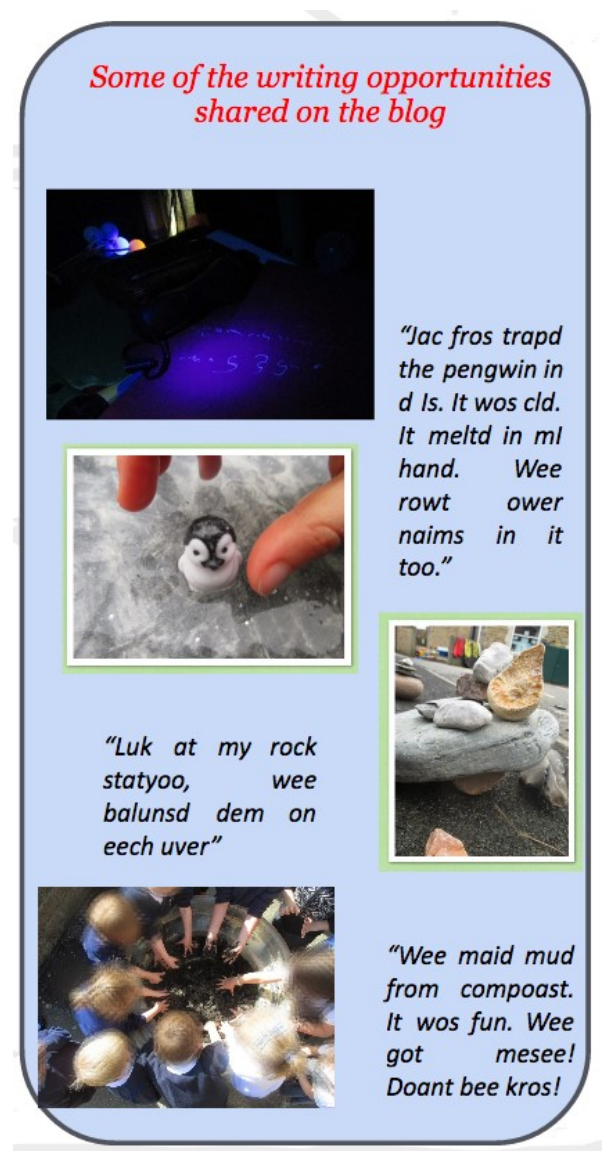

Figure 5: Early Years children blogging

One school used an online company to print copies of children's stories as books, and these were often chosen for reading aloud to the group. Technology also made it possible for children to use film and media as a means of expression, and as an inspiration for writing, often with embedded writing opportunities such as creating storyboards, captions and scripts. As an example, the app Morfo was used to bring an imaginary superhero to life so that he could respond to children's writing. Activities such as these gave children a real sense of purpose. 
What can be summarised from this case study is that technology can be used to support social learning in diverse contexts. It illustrates how technology can pave the way for fluid learning journeys across layers of related communities. In this project, the online community bound together the professional development group's activities, helping them to move their practice forwards together in a timely way through a balance of talking and doing within their authentic classroom contexts. Technology also provided a platform for them to make secure links with their associated communities of children, parents and local partners.

\section{Digital links between children's overlapping communities: home and early years settings}

Several researchers identify a gap between home and school use of technology in the early years. For example, Marsh et al., (2015:3) found that only 3\% of parents reported that their children had access to mobile technologies such as iPads in early years settings they attended. Supporting this notion is Plowman et al.'s research (2012) which indicates that children have a richer opportunity to engage with mobile technologies in the home, compared to their experience in early years settings. To strengthen the link between technology use within the home and school communities, practitioners need to recognise the considerable amount of learning that occurs outside the setting, as learning happens all the time and is influenced by the environment, culture, people and situations. It is important for practitioners to acknowledge children's prior knowledge and home experiences of digital technologies before they can begin to support and plan for children's development.

Practitioners build up expertise in how young children learn and how each child operates within their setting. However it is the parent who knows their child best, and unless there is a sharing of information between practitioners and parents, a child's developmental needs will be neither fully understood nor, ultimately, supported. Practitioners also need to work with parents so they understand how the technology is used with the children at the setting. It may not always be possible for practitioners to speak to parents on a day-to-day basis about their child's learning, current interests or recent experiences and technology can play a part in strengthening links between the two communities and ensuring this communication is continuous.

Early Years settings and schools can use a variety of media, such as ePortolios, blogs, web pages and online learning journals, to provide opportunities to extend face to face interactions 
between home and the setting. These digital channels of communication enhance and enrich opportunities to share episodes in children's lives in a two-directional way between home and settings or schools. They can also help to build a trusting relationship, allowing the parent to get to know the practitioner who is looking after their child each day. This also works the other way round; many parents will share their children's home experiences and achievements, enabling the practitioner to gain a better understanding of the child's home life. This can be beneficial for the parents in feeling that they can talk to the practitioner and gain support where needed.

With the advancement of mobile apps, it is now possible to go beyond the typical methods of sharing information between the setting and home. Innovative use of apps can support interaction between communities of practitioners and families. The vignette below provides an example of how a setting can use an app to build a community between the setting, children and families:

\section{Vignette 3}

ClassDojo is a communication app for the classroom; it connects teachers, parents, and children who use it to share photos, videos, and messages throughout the day. They use ClassDojo to work together as a team, share in the classroom experience, and to bring ideas to life in their classrooms and homes (ClassDojo, 2017). Class Dojo even translates messages in many different languages which cuts across language barriers.

However, whether it is parents or children the settings are contacting, networking online also brings risks. The National Association of Schoolmasters Union of Women Teachers (NASUWT) offers an advice pack to practitioners on staying safe online (https://www.nasuwt.org.uk/article-listing/using-social-media-safely.html). They suggest that it is important to make sure protocols are in place and those in charge of the school or setting's social media accounts fully understand their workings and are vigilant about monitoring. Parents may feel concerned about their children's images being posted online, but most fears are put aside once the security policies are discussed.

\section{Points for reflection}


- Is your online communication an extension of the information that you share face to face with parents?

- Which issues concern you about social media?

\section{Conclusion}

Technology has the potential to support young children's learning and enhance their relationships with adults and with their peers. However, integrating technology into children's learning requires a great deal of thought and commitment from practitioners. They may need support in learning how to use it innovatively to create conditions for social learning and how to nurture the development of communities of practice within their settings. A key idea is that technology should not compete with children's physical exploration of the world; rather it should facilitate the learning that accompanies their real-world engagement by providing a platform for capturing, sharing and reflecting. For children's learning experiences to be rewarding, early childhood practitioners need to provide sensitive support and carefully weave technology into the fabric of their practice. A question for early childhood practitioners to consider is 'what type of experiences in the early years support young children's learning and what might the use of technology add?'

By joining in conversations around this question via online communities of practice with their own peers, practitioners can tap into a rich seam of professional development. Online CoPs offer a chance to engage with new audiences and produce digital artefacts that reflect shared experiences. For the community to thrive, it must have a clear purpose; participants need to know why they are there, how they can contribute, and what they can expect.

Parents' engagement in their children's learning is paramount, and technology can strengthen the three-way relationship between parents, schools and learners. Online sharing with parents is not a substitute for face to face contact, but it can act as an additional mode of communication that enables parents to join in with the children's learning journeys, facilitating a deeper understanding of how best to meet the child's learning, developmental and emotional needs, both in the setting and at home.

\section{References}


Alliance for Childhood. (2010). Campaign for a commercial-free childhood. [online] Available from: http://www.allianceforchildhood.org/ .

Araujo, L. (1998). Knowing and learning as networking. Management Learning, 29(3), 317336.

Berk, L., E. (2012) Infants and children: Prenatal through middle childhood. Boston, MA: Pearson.

Buckingham, D (2004) The media literacy of children and young people: A review of the research literature on behalf of Ofcom. London: Centre for the Study of Children.

Carter Olson, C. (2016) \#BringingBackOurGirls: digital communities supporting real-world change and influencing mainstream media agendas. Feminist Media Studies, 16(5), pp.772787

Chiong, C., Ree, J., Takeuchi, L., \& Erickson, I. (2012) Print books vs. e-books: Comparing parent-child cop-reading on print, basic, and enhanced e-book platforms. New York: The Joan Ganz Cooney Center.

Clarke, B., Svanaes, S. and Zimmerman, S. (2013). One to one tablets in education: The Global Picture. London: Techknowledge for Schools.

Class Dojo (2017) [online] Available from: https://www.classdojo.com/en$\mathrm{gb} /$ about/?redirect=true.

Cox, S. and Galda, L. (1990) Multicultural literature: Mirrors and windows on a global community (Children's books). Reading Teacher , 43 (8) p582-89,

Dhir, A., Gahwaji, N., M. \& Nyman, G. (2013). The Role of the iPad in the hands of the learner. Journal of Universal Computer Science, 19, (5): 706-727. 
Flewitt, R., Messer, D., \& Kucirkova, N. (2014). New directions for early literacy in a digital age: the iPad. Journal of Early Childhood Literacy, 0 (0):1 - 22.

Galloway, J. (2009). Harnessing technology for every child matters and personalised learning. New York: David Fulton Pub.

Hutchison, A. Beschorner, B. and Schmidt-Crawford, D. (2012) Exploring the use of the iPad for literacy learning. The Reading Teacher, 66(1): 15-23.

Johnson, C. M. (2001). A survey of current research on online communities of practice. The Internet and Higher Education, 4(1), 45-60.

Kress G. (2010). Multimodality. A social semiotic approach to contemporary communication. London: Routledge.

Linn, S., Poussaint, A.F. (1999). The Trouble With Teletubbies. The American prospect. [online]. Available from: http://prospect.org/article/trouble-teletubbies

Magos, K., Tsilimeni, T. and Spanopoulou, K.(2013) 'Good morning Alex - Kalimera Maria': digital communities and intercultural dimensions in early childhood education. Intercultural Education, 24 (4), pp. 366-373, DOI: 10.1080/14675986.2013.812401

Marsh, J., Plowman, L., Yamada-Rice, D., Bishop, J.C., Lahmar, J., Scott, F., Davenport, A., Davis, S., French, K., Piras, M., Thornhill, S., Robinson, P. and Winter, P. (2015) Exploring Play and Creativity in Pre-Schoolers' Use of Apps: Report for Early Years Practitioners. [online] Available from: http://www.techandplay.org/reports/TAP_Early_Years_Report.pdf

McPake, J., Plowman, L., \& Stephen, C. (2013). Pre-school children creating and communicating with digital technologies in the home. British Journal of Educational Technology, 44: 421-431.

Michael Cohen Group \& U.S. Department of Education (2011). Touch Screen Technology: Young Children, Apps, \& iPads. New York: Michael Cohen Group. 
Mitra, S. (2012). Beyond the Hole in the Wall: Discover the Power of Self-Organized Learning. London: TED Books.

Neumann, M. (2014) An examination of touch screen tablets and emergent literacy in Australian pre-school children. Australian Journal of Education, 0 (0):1-14.

Parette, H., P., Quesenberry, A., C. \& Blum, C. (2010) Missing the boat with technology usage in early childhood settings: A 21 st century view of developmentally appropriate practice. Early Childhood Education Journal 37: 335-343.

Plowman, L., Stevenson, O., Stephen, C., \& McPake, J. (2012). Pre-school children's learning with technology at home. Computers and Education, 59: 30-37.

Saadatmand, M., \& Kumpulainen, K. (2014). Participants' perceptions of learning and networking in connectivist MOOCs. MERLOT Journal of Online Learning and Teaching, $10(1), 16-30$

Sharples, M., Graber, R., Harrison, C. \& Logan, K. (2009) E-Safety and Web 2.0 for Children Aged 11-16. Journal of Computer Assisted Learning, 25 (1): 70-84.

Sigman A. (2012). The impact of screen media on children: a Eurovision for parliament. In: Clouder C, Heys, B. Matthes, M. \& Sullivan, P. (2012) eds. Improving the quality of childhood in Europe. East Sussex: European Parliament Working Group on the Quality of Childhood in the European Union.

Smith and Gasser (2005) The development of embodied cognition: Six lessons from babies. Institute of Technology, 11: 13-29.

Smith, S.U., Hayes, S. and Shea, P., 2017. A critical review of the use of Wenger's Community of Practice $(\mathrm{CoP})$ theoretical framework in online and blended learning research, 2000-2014. Online Learning, 21(1).

Tahnk, J. L. (2011) Digital milestones: Raising a tech-savvy kid. Parenting Early Years, 25: $78-84$ 
Triggs, P., \& John, P. (2004). From Transaction to Transformation: ICT, Professional development and the formation of Communities of Practice. Journal of Computer Assisted Learning. 20(6), 426-439.

Vygotsky, L. (1981) The Genesis of Higher Mental Functions, in J.V. Wertsch (Ed.) The Concept of Activity in Soviet Psychology. New York: M.E. Sharpe.

Wenger E. (1998). Communities of practice: Learning, meaning and identity. New York, NY: Cambridge University Press.Wenger E. (2000). Communities of practice and social learning systems. Organization, 1 7, 2, 225-246.

Wenger, E. (2014) Communities of practice: a brief introduction. [Online] Available from: http://wenger-trayner.com/wp-content/uploads/2013/10/06-Brief-introduction-tocommunities-of-practice.pdf.

Wenger, E., White, N., \& Smith, J. D. (2009). Digital habitats: Stewarding technology for communities. CPsquare. 